\title{
Modulation of pain processing in hyperalgesia by cognitive demand
}

\author{
Katja Wiech, ${ }^{\mathrm{a}, *}$ Ben Seymour, ${ }^{\mathrm{a}}$ Raffael Kalisch, ${ }^{\mathrm{a}}$ Klaas Enno Stephan, ${ }^{\mathrm{a}}$ Martin Koltzenburg, ${ }^{\mathrm{b}}$ \\ Jon Driver, ${ }^{\mathrm{a}, \mathrm{c}}$ and Raymond J. Dolan ${ }^{\mathrm{a}}$ \\ ${ }^{a}$ Wellcome Department of Imaging Neuroscience, Institute of Neurology, UCL, 12 Queen Square, London WC1N 3BG, UK \\ ${ }^{\mathrm{b}}$ Institute of Child Health, University College London, UK \\ ${ }^{\mathrm{c}}$ Institute of Cognitive Neuroscience and Department of Psychology, University College London, UK
}

Received 23 August 2004; revised 7 March 2005; accepted 28 March 2005

Available online 22 June 2005

\begin{abstract}
The relationship between pain and cognitive function is of theoretical and clinical interest, exemplified by observations that attentiondemanding activities reduce pain in chronically afflicted patients. Previous studies have concentrated on phasic pain, which bears little correspondence to clinical pain conditions. Indeed, phasic pain is often associated with differential or opposing effects to tonic pain in behavioral, lesion, and pharmacological studies. To address how cognitive engagement interacts with tonic pain, we assessed the influence of an attention-demanding cognitive task on pain-evoked neural responses in an experimental model of chronic pain, the capsaicin-induced heat hyperalgesia model. Using functional magnetic resonance imaging (fMRI), we show that activity in the orbitofrontal and medial prefrontal cortices, insula, and cerebellum correlates with the intensity of tonic pain. This pain-related activity in medial prefrontal cortex and cerebellum was modulated by the demand level of the cognitive task. Our findings highlight a role for these structures in the integration of motivational and cognitive functions associated with a physiological state of injury. Within the limitations of an experimental model of pain, we suggest that the findings are relevant to understanding both the neurobiology and pathophysiology of chronic pain and its amelioration by cognitive strategies.

(c) 2005 Elsevier Inc. All rights reserved.
\end{abstract}

Keywords: Cognitive demand; Hyperalgesia; Pain; fMRI; Capsaicin

\section{Introduction}

The suggestion that pain and cognitive performance share key neural mechanisms is demonstrated by their reciprocal interaction, observed in experimental and clinical settings. For instance, performance of cognitive tasks can be impaired during pain (Crombez et al., 1997; Lorenz and Bromm, 1997), and patients with chronic pain often report cognitive deficits including

\footnotetext{
* Corresponding author. Fax: +44 2078131420 .

E-mail address: kwiech@fil.ion.ucl.ac.uk (K. Wiech).

Available online on ScienceDirect (www.sciencedirect.com).
}

concentration and memory problems (Dick et al., 2002; Grace et al., 1999; Grigsby et al., 1995; Kewman et al., 1991). Conversely, subjective pain intensity is reduced during performance of a cognitive task (Eccleston, 1995; Hodes et al., 1990; Terkelsen et al., 2004). Furthermore, persistently heightened attention towards pain has been proposed as an important factor for the maintenance of chronic pain (Crombez et al., 2004; Dehghani et al., 2003; Hasenbring, 2000; Vlaeyen and Linton, 2000). Understanding the mutual relationship between pain and cognition is thus of substantial interest with respect to both neurobiological and psychological processes underlying chronic pain.

Recent neuroimaging studies investigating mechanisms underlying attentional modulation of pain indicate that the execution of an attention-demanding task can modulate pain-related activity in anterior cingulate cortex, insula, and orbitofrontal cortex (Bantick et al., 2002; Brooks et al., 2002; Petrovic et al., 2000; Remy et al., 2003; Valet et al., 2004) and less consistently, somatosensory association cortices (Petrovic et al., 2000), thalamus, hippocampus, cerebellum (Bantick et al., 2002), and periaqueductal gray (Tracey et al., 2002). Although the significance of cognitive modulation is mainly discussed in the context of chronic clinical pain, the above neuroimaging studies used relatively short-lasting noxious stimuli to induce pain. However, a growing body of evidence indicates that the neurobiological mechanisms of acute and chronic pain differ substantially at all levels of the neuraxis including the brain (Altier and Stewart, 1999; Hunt and Mantyh, 2001; Woolf and Salter, 2000), probably reflecting their different behavioral functions: the largely conservative and recuperative behavior associated with chronic pain and the arousal and engagement in defensive behavior typically associated with acute pain.

Application of the pungent chemical capsaicin has been used extensively in human volunteers to model sensory symptoms of neuropathic or inflammatory pain (Koltzenburg et al., 1994; Petersen and Rowbotham, 1999; Simone et al., 1989). The tonic pain induced by capsaicin is therefore understood as an experimental approximation to chronic pain. Microneurographic recordings in humans have shown that the magnitude of capsaicin-induced pain is signaled by a subgroup of unmyelinated mechanically insensitive afferents (MIAs; Schmelz et al., 2000). 
Importantly, it is the excitation of these MIAs - and not of the common type of polymodal nociceptors - that leads to central sensitization (Klede et al., 2003; Koppert et al., 2001; LaMotte et al., 1991). The capsaicin model has previously been used in functional neuroimaging studies to investigate subcortical and cortical correlates of this sensitization in mechanical hyperalgesia (Baron et al., 1999; Witting et al., 2001) and cluster headache (May et al., 2000). Recently, Lorenz and coworkers (Lorenz et al., 2002) used neuroimaging to compare brain responses to heat stimuli applied to capsaicin-treated and untreated skin. Even though both types of stimuli were calibrated to the same subjective intensity level, pretreatment with capsaicin induced unique activity in medial thalamic, orbitofrontal, medial prefrontal, perigenual cingulate, anterior insula, and dorsolateral prefrontal cortices. These key findings suggest that this network of brain regions is involved in mediating the response to (the capsaicin model of) chronic inflammatory pain, and may reflect a more complex cognitive and emotional response to nociceptive input from sensitized afferent fibers.

The present study sought to extend these findings by investigating the network of brain areas that specifically reflects the intensity of tonic pain in capsaicin-induced hyperalgesia, while critically, manipulating the cognitive demand (or 'attentional load'; cf. Lavie, 1995; Rees et al., 1997) via the difficulty level of a concurrent task.

\section{Materials and methods}

\section{Subjects}

Fifteen healthy right-handed volunteers ( 5 females, 10 males, mean age: 26.7 , range: $20-47$ years) were recruited for the functional imaging study. An additional eleven subjects ( 3 female, 8 male, mean age: 28.6 , range: $18-42$ years) took part in a separate behavioral study. This research was approved by the Joint Ethics Committee of the Institute of Neurology and National Hospital for Neurology and Neurosurgery, London. All subjects gave written informed consent according to the Declaration of Helsinki.

\section{Study design}

The effect of an attention-demanding task on pain in hyperalgesia was tested in a $2 \times 2$ factorial design (Fig. 1), with the

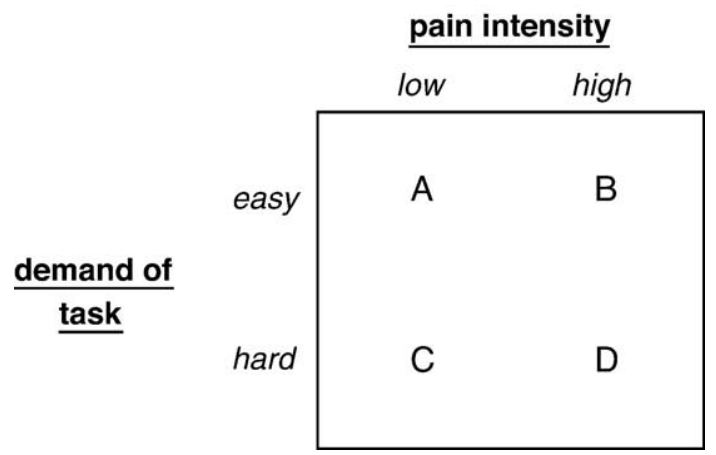

Fig. 1. Design of the study. The study involves a $2 \times 2$ factorial design, with factors PAIN INTENSITY (high vs. low intensity) and DEMAND OF CONCURRENT COGNITIVE TASK (hard vs. easy task). factors PAIN INTENSITY (low vs. high intensity) and DEMAND OF CONCURRENT COGNITIVE TASK (easy vs. hard task). The experiment was divided into four sessions, each of approximately $7 \mathrm{~min}$ duration. In each session, subjects had to perform a concurrent cognitive task of high or low cognitive demand, while they received the painful tonic heat stimulus. All four possible combinations of the two experimental factors (low or high pain intensity and easy or hard task) were presented in a blocked fashion with three repetitions of each condition per session.

To assess whether performance of the highly demanding cognitive task reliably led to lower pain intensity ratings, we performed a behavioral pilot study (separate from the imaging study). The design of the behavioral and the fMRI experiment were identical except that subjects had to rate the perceived intensity of the heat stimuli on a Numerical Rating Scale (NRS) after each trial in the behavioral test. Although it might have limited the comparability between the two studies, we decided not to obtain pain ratings during the fMRI experiment, in order to avoid interference effects between the functional activations of interest and the evaluative processes underlying the rating. In order to ensure a test environment similar to the situation in the MRI scanner, the characteristic scanner noise was presented to the subjects via headphones during the behavioral study.

\section{Pain stimuli}

In order to induce hyperalgesia, we topically applied $1 \%$ capsaicin (8-methyl- $N$-vanillyl-6-nonenamide, 98\%, SigmaAldrich, Gillingham, United Kingdom, diluted in a mixture of $5 \%$ ethanol-KY jelly) to the medial side of the left forearm 30 min prior to the experiment. Capsaicin was spread over an area of $2.5 \times 5 \mathrm{~cm}$ and the treated skin area was covered with a plastic film to avoid evaporation of capsaicin during residence time. Capsaicin activates unmyelinated polymodal C-fiber afferents (Fitzgerald, 1983) and induces by itself a burning sensation (Frot et al., 2004). The intensity of the induced pain can be varied by a heat stimulus leading to an increase in pain (Petersen and Rowbotham, 1999).

Heat stimuli were applied to the capsaicin-treated site by using a peltier thermode (MSA thermotest, Somedic, Sweden; surface of $2.5 \times 5 \mathrm{~cm})$ adapted for use in an MR scanner environment. It was fixed to the forearm by a tourniquet so that subjects could easily remove the device in case the temperature reached an intolerable level. To adapt the heat levels to the sensitivity of each subject, we readjusted the temperature for low- and high-intensity levels prior to each session. Starting from a temperature of $20^{\circ} \mathrm{C}$, stimuli of $5 \mathrm{~s}$ duration were applied using temperature increments of $0.5^{\circ} \mathrm{C}$ until the temperature reached an intolerable level. Subjects rated the perceived intensity of each heat stimulus on a Numerical Rating Scale (NRS) ranging from 0 (='no pain') to 10 (='worst imaginable pain'). Temperature levels that were rated as NRS 4 and NRS 8 were chosen as low and high pain levels, respectively, for each subject. Temperature was set to a baseline level of $20^{\circ} \mathrm{C}$ which was rated as non-painful by all subjects. Five seconds prior to each task block, the temperature increased at a rate of $5^{\circ} \mathrm{C} / \mathrm{s}$ until the appropriate temperature (low or high pain level) was reached.

This procedure ensured that the change in temperature was completed before the task performance started. The temperature was kept constant during the 21-s block of task performance and 
then dropped to $20^{\circ} \mathrm{C}$ baseline at a rate of $5^{\circ} \mathrm{C} / \mathrm{s}$. The purpose of the 3 -s cooling period in-between trials was mainly to indicate the end of a trial and did not stop the pain sensation completely. Previous work determined that the abolition of capsaicin-evoked pain during mild cooling can be fully attributed to the decreased activity of peripheral nociceptors and is not the consequence of a central nervous mechanism (Koltzenburg et al., 1992; LaMotte et al., 1992).

\section{Concurrent attention tasks of high or low cognitive load}

Subjects performed Rapid Serial Visual Processing (RSVP) tasks at central fixation during each 21-s block, each consisting of a stream of 40 stimuli ('T's) presented at the fixation point (Fig. 2). The 'T's were of different colors (light blue, dark blue, light green, dark green, red) and each either upright or inverted, resulting in 10 possible stimuli. Each ' $\mathrm{T}$ ' was presented for 200 $\mathrm{ms}$, followed by an interval of $300 \mathrm{~ms}$ between stimuli. The different stimuli were presented in a random order, with the constraint that two 'target' stimuli (see below) did not appear sequentially after each other. Before each trial, two target letters were shown on the computer screen for $5 \mathrm{~s}$. In the conditions with low cognitive demand (i.e., easy task), the subjects had to detect upright and inverted red Ts. For the high cognitive demand conditions (i.e., hard task), two different sets of targets were defined, both requiring specific combinations of orientation and color to be detected, not just any red letter as in the lowload task. In half of the trials, the participants had to press the button when an upright dark blue or an inverted dark green $\mathrm{T}$ was displayed, whereas in the other half of the trials, the inverted dark blue and the upright dark green were targets. The subjects were instructed to respond to every target as quickly as possible, via a button press with the non-stimulated arm. Before the experiment, all subjects were shown all stimulus types, were familiarized with the stimulus presentation, and practiced the task. As a measure of task performance, we recorded reaction times (RTs) for button presses in response to each target, plus the number of targets that were missed and number of falsepositive key presses.

\section{Data acquisition}

MR scanning was performed on a 1.5-T scanner (Siemens Sonata, Erlangen, Germany). In a single session, 100 volumes (48 contiguous, axial, 2-mm-thick slices each; $1 \mathrm{~mm}$ gap) were acquired using a gradient echo-planar imaging (EPI) T2* sensitive sequence [repetition time TR: $90 \mathrm{~ms}$ per slice resulting in a TR(total) of $4.32 \mathrm{~s}$; TE $=50 \mathrm{~ms}$; flip angle: 90 matrix: $64 \times 64$; field of view: $192 \mathrm{~mm}^{2}$, tilted $-30^{\circ}$ from intracommissural plane to minimize signal dropout in orbitofrontal cortex; Deichmann et al., 2003]. A standard coil was used and packed with foam pads. Subjects wore MRcompatible electrostatic headphones to attenuate the scanner noise. A high-resolution $(1 \times 1 \times 1 \mathrm{~mm}$ voxel size $) \mathrm{T} 1-$ weighted structural MRI was acquired using a three-dimensional sequence (3D-MDEFT, 176 partitions, matrix: $256 \times 224$, field of view: $256 \times 224 \mathrm{~mm}$, slab thickness: $176 \mathrm{~mm}$; Deichmann et al., 2004). These structural images were coregistered with the mean EPI from the functional acquisition, normalized into a standard space using the normalization parameters applied to the EPIs and subsequently averaged for overlay of statistical parametric maps.

\section{Data analysis}

For the behavioral data, repeated measurement ANOVA with within-subject factors of PAIN INTENSITY (high vs. low intensity) and DEMAND OF CONCURRENT COGNITIVE TASK (hard vs. easy task) was used to analyze subjective stimulus intensity ratings, and likewise for reaction times,

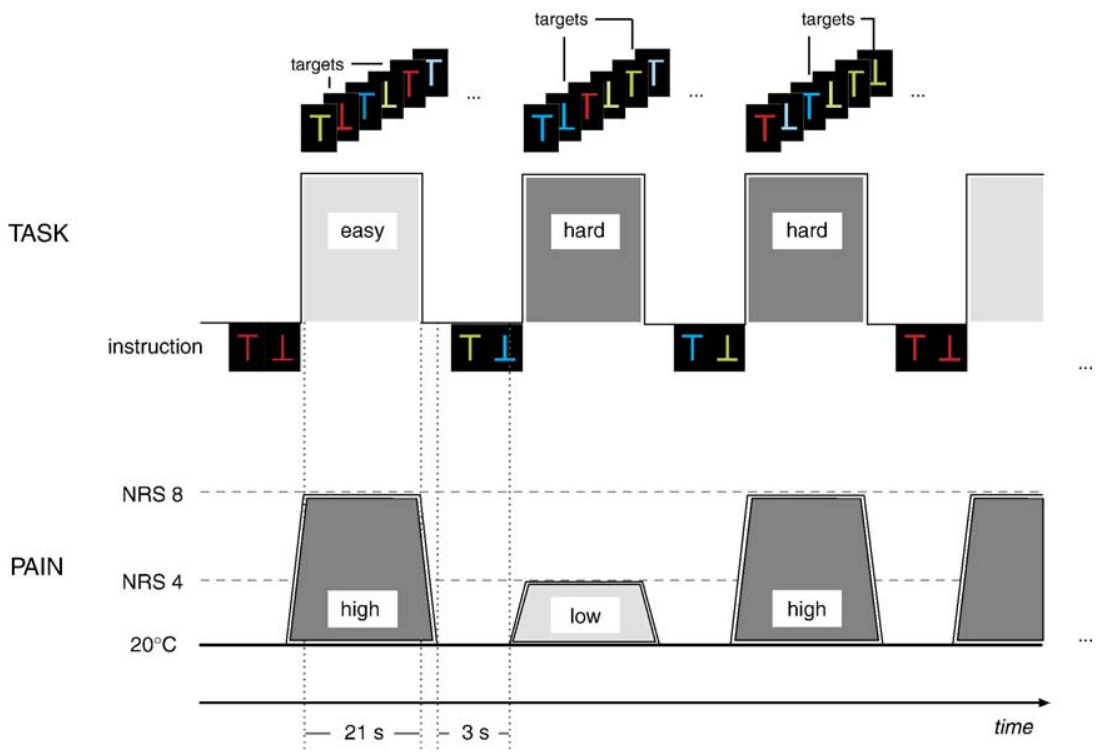

Fig. 2. Section of a session. The figure shows an example of a session. Easy and hard tasks had to be performed during application of low- or high-level pain stimulation, respectively. Prior to the start of a block, two target letters were presented for $5 \mathrm{~s}$ ('instruction'). During each block, a stream of 'T's was presented which were of different orientation and color. The subjects were instructed to press a button whenever one of the target letters appeared on the screen. Between two consecutive blocks, the temperature of the thermode was lowered to a non-painful level $\left(20^{\circ} \mathrm{C}\right)$ for $3 \mathrm{~s}$. Note that the cognitive task starts after the temperature of the thermode has reached the appropriate temperature. NRS: Numerical Rating Scale. 
number of missed targets and false-positive button presses in the RSVP tasks.

For analysis of neuroimaging data, the first five volumes of each session were discarded to suppress $T_{1}$ relaxation effects. All volumes were realigned to the first volume (Friston et al., 1995a). A mean image was created using realigned volumes. The functional images were spatially normalized (Friston et al., 1995a) to templates in a space defined by a template from the Montreal Neurological Institute (MNI; Evans et al., 1993), using 12 affine parameters and a set of nonlinear basis functions. For the assessment of single subject data, normalized first-level EPI-images were smoothed by using a 6-mm FWHM (full-width at half maximum) Gaussian kernel (data are not presented). In a second step, first-level contrast images were smoothed using an 8-mm kernel to reduce residual variability after spatial normalization, and to permit application of Gaussian random field theory for statistical analysis (Friston et al., 1995b). This two-step procedure resulted in an effective smoothing of $10 \mathrm{~mm}$.

At the first level, contrast images were calculated for the two main effects (PAIN INTENSITY: high minus low intensity, collapsed over the two task difficulty levels; and DEMAND OF CONCURRENT COGNITIVE TASK: hard minus easy task, collapsed over the two pain intensity levels), and also for the interactions [(high - low pain) easy task - (high - low pain $)_{\text {hard task }}$ and [(high - low pain $)_{\text {hard task }}$ - (high - low pain) easy task]. For random effects analysis at the second level, these images were then entered into one-sample $t$ tests. Nuisance covariates included the realignment parameters to account for any motion artifacts.

Coordinates are reported in millimeters, relative to the anterior commissure, according to the template used for spatial normalization (Evans et al., 1993). We initially set statistical thresholds at $P<0.05$ cluster-level corrected for multiple comparisons across the whole brain (with $P<0.001$ at the voxel level). For the critical interactions expected, all clusters were reported that exceeded a threshold of $P<0.001$ (uncorrected) at the voxel level and had an extent of $\geq 10$ contiguous voxels. For descriptive purposes, we report activations at $P<0.005$ (uncorrected) for the main effect of PAIN INTENSITY and the associated interactions with the task.

\section{Results}

\section{Behavioral results}

During behavioral testing, subjects gave greater intensity ratings for high- compared to low-intensity heat stimulation [main effect PAIN INTENSITY: $F(1,10)=121.80, P<0.001$; Fig. 3], as expected. Importantly, pain intensity ratings were also different between the two task difficulty levels [main effect DEMAND OF CONCURRENT COGNITIVE TASK: $F(1,10)=$ $7.56, P<0.05$ ] with higher intensity ratings during performance of the easy compared to the hard task. As indicated by the significant interaction [DEMAND OF CONCURRENT COGNITIVE TASK $\times$ PAIN INTENSITY: $F(1,10)=17.42, P<0.01$ ], the effect of the simultaneously performed cognitive task on the perceived intensity of the applied noxious stimuli differed between the two stimulus intensities. Post hoc tests revealed that the difference in pain intensity ratings between the easy and
Pain intensity ratings

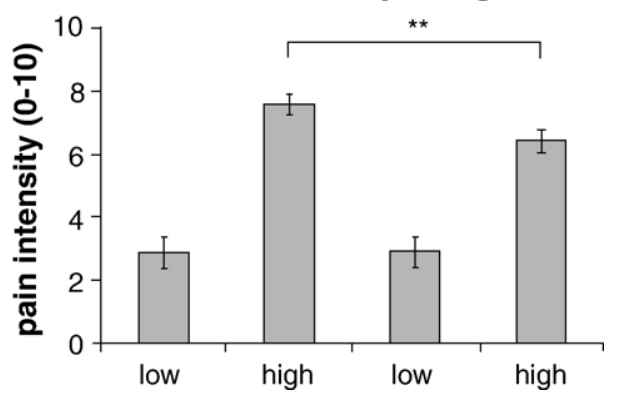

Fig. 3. Pain ratings of the behavioral study. Subjects rated the perceived intensity of stimulation on a Numerical Rating Scale (NRS) with the endpoints $0=$ 'no pain' and $10=$ 'worst imaginable pain'. The perceived pain intensity was significantly higher during performance of the easy compared to the hard task. The difference between both task difficulty levels was more pronounced when high-level pain was applied: During performance of the less demanding task, subjects rated the stimulation as more intense than during the hard task. $* *=P<0.01$.

hard task condition only occurred when high-level pain was applied: Subjects rated the high intensity as less painful when they performed the hard task $[t(10)=4.04, P<0.01]$, suggesting some 'interference' effect by the high-load cognitive task. For low-level pain stimulation, we did not find any difference between the two task difficulty levels $[t(10)=-0.26$, $P>0.05]$.

Analysis of the behavioral data during scanning showed as expected a difference in level of performance for the hard vs. easy task (main effect of DEMAND OF CONCURRENT COGNITIVE TASK) for all three measures [RT: $F(1,14)=122.83, P<0.001$, missed targets: $F(1,14)=43.19, P<0.001$, false-positive responses: $F(1,14)=42.51, P<0.001$; see Table 1]. None of these performance measures showed a main effect of PAIN INTENSITY nor was there a significant interaction. However, for the number of false-positive responses, the interaction between pain level and task difficulty approached significance $[F(1,14)=$ 3.93, $P=0.067$, with a trend for more positive responses under high pain for the difficult task.

\section{Functional imaging results}

\section{Main effect of PAIN INTENSITY}

The comparison of high vs. low pain collapsing across both task difficulty levels (i.e., $[(B+D)-(A+C)]$; see Fig. 1) showed activation in the right mid-posterior insula, encompassing the parieto-temporal operculum and extending into the temporal pole, medial prefrontal and orbitofrontal cortices, as well as right cerebellum (see Fig. 4). Thus, the signal level in these brain regions increased with higher pain level regardless of the task difficulty level. At a more liberal threshold, additional activations were observed in contralateral SI, thalamus, mid and rostral ACC, right DLPFC, and left premotor cortex (see Table 2). The reverse contrast, testing for areas showing greater activation during low compared to high pain levels, did not reveal significant effects on a cluster-level threshold of $P<0.05$. In an exploratory analysis with an adapted threshold of $P<0.005$, lower activations during highlevel pain stimulation were found in the ipsilateral SI and temporal lobe (see Table 2). 
Table 1

Performance measures: number of missed targets, and false-positive responses per block as well as reactions times (in milliseconds)

\begin{tabular}{lrr}
\hline & $M$ & SD \\
\hline Missed targets & & \\
Easy task, low pain & 1.80 & 2.68 \\
Easy task, high pain & 0.93 & 1.67 \\
Hard task, low pain & 19.07 & 12.18 \\
Hard task, high pain & 18.60 & 10.84 \\
& & \\
False-positive responses & & \\
Easy task, low pain & 2.20 & 2.81 \\
Easy task, high pain & 1.13 & 1.77 \\
Hard task, low pain & 16.60 & 8.99 \\
Hard task, high pain & 18.87 & \\
& & \\
Reactions times (in milliseconds) & & 23.92 \\
Easy task, low pain & 380.39 & 24.20 \\
Easy task, high pain & 385.54 & 47.88 \\
Hard task, low pain & 503.32 & 46.25 \\
Hard task, high pain & 505.36 &
\end{tabular}

$M=$ mean, $\mathrm{SD}=$ standard deviation.

Main effect of DEMAND OF CONCURRENT COGNITIVE TASK

The contrast of high vs. low difficulty for the RSVP visual task at fixation, collapsing across the low- and high-temperature conditions (i.e., $[(C+D)-(A+B)]$; see Fig. 1) revealed enhanced activation in premotor cortex extending into dorso- lateral prefrontal cortex, as well as in occipital regions, inferior and superior parietal lobe, insula, frontal operculum, bilateral thalamus, and cerebellum. Hence, regardless of the pain intensity level, these brain regions showed increased signal level when the subjects performed the more demanding cognitive task on the visual stimuli. Enhanced activation for the easy compared to the hard task was observed in superior frontal and temporal lobe, posterior cingulate cortex, angular gyrus, and cerebellum. Activation maxima and maximum $z$ values are given in Table 2.

\section{Interaction of PAIN INTENSITY and DEMAND OF CONCURRENT COGNITIVE TASK}

A significant interaction [(high - low pain $)_{\text {easy task }}-($ high low pain $)_{\text {hard task }}$, i.e., $(B-A)-(D-C)$ (see Fig. 1) was observed in left medial prefrontal cortex and left cerebellum $(P<$ 0.001 ; Fig. 5, Table 3). This indicates that the pain-related activation in both brain regions was higher during performance of the easy compared to the hard task. To further characterize this interaction, the mean parameter estimates for the peak voxel of both activation clusters were plotted. As shown in Fig. 5, the interaction in medial prefrontal cortex and cerebellum is driven by a difference between the two high-intensity pain conditions. Note that when the more intense pain stimuli were applied during performance of the hard cognitive task, neural activity was attenuated. At a lower threshold, significant interactions for the interaction [(high - low pain $)_{\text {easy task }}$ - (high - low pain $)_{\text {hard task }}$ were observed in the left thalamus, DMPFC, and caudate
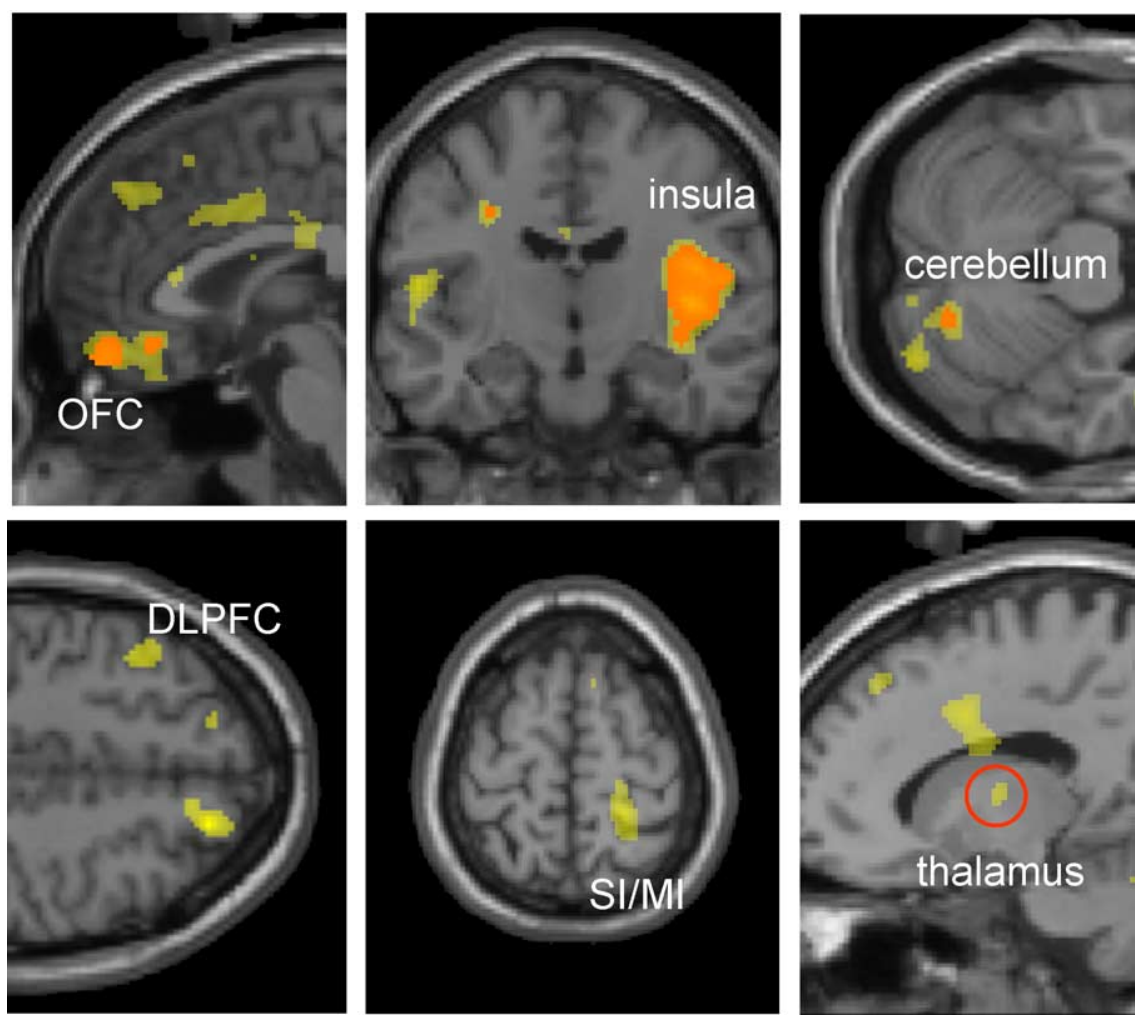

Fig. 4. Main effect of PAIN INTENSITY. High-level compared to low-level pain leads to stronger activations in the right insula, left orbitofrontal cortex, and right cerebellum $(P<0.05$ cluster-level corrected for multiple comparisons across the whole brain with $P<0.001$ at the voxel level; shown in orange). On a lower significance level $(P<0.005$, uncorrected; minimal cluster size: 10 voxels; shown in yellow), additional activations emerged in the dorsolateral prefrontal cortex (DLPFC), primary somatosensory and motor cortices (SI/MI), thalamus, and other regions (see Table 2). 
Table 2

Main effect of PAIN INTENSITY

\begin{tabular}{|c|c|c|c|c|c|c|c|}
\hline \multirow[t]{2}{*}{ Brain region } & \multirow[t]{2}{*}{ Laterality } & \multirow[t]{2}{*}{ Brodmann area } & \multicolumn{3}{|c|}{ Talairach coordinates } & \multirow[t]{2}{*}{ Cluster size } & \multirow[t]{2}{*}{ Max. Z } \\
\hline & & & $x$ & $y$ & $z$ & & \\
\hline \multicolumn{8}{|l|}{ High pain > low pain } \\
\hline \multirow[t]{6}{*}{ DLPFC } & $\mathrm{R}$ & 9 & 20 & 36 & 48 & 457 & 4.83 \\
\hline & & & 14 & 30 & 48 & - & 3.60 \\
\hline & & & 32 & 48 & 38 & - & 3.15 \\
\hline & $\mathrm{L}$ & $9 / 46$ & -18 & 30 & 52 & 231 & 3.42 \\
\hline & & & -38 & 42 & 36 & - & 3.08 \\
\hline & & & -28 & 38 & 48 & - & 2.83 \\
\hline \multirow[t]{7}{*}{ Insula } & $\mathrm{R}$ & 48 & 38 & -16 & 8 & 4641 & $4.69^{*}$ \\
\hline & & & 36 & -20 & 0 & - & 4.64 \\
\hline & & & 52 & -26 & 16 & - & 4.56 \\
\hline & $\mathrm{L}$ & 48 & -54 & -12 & 10 & 294 & 3.91 \\
\hline & & & -50 & -28 & 14 & - & 3.27 \\
\hline & & & -44 & -18 & 14 & - & 3.23 \\
\hline & $\mathrm{L}$ & 48 & -40 & 14 & -6 & 66 & 3.16 \\
\hline \multirow[t]{3}{*}{$\mathrm{ACC} / \mathrm{OFC}$} & $\mathrm{R} / \mathrm{L}$ & $32 / 11$ & -2 & 54 & -14 & 834 & $4.00 *$ \\
\hline & & & -2 & 36 & -12 & - & 3.54 \\
\hline & & & 8 & 38 & -10 & - & 3.39 \\
\hline \multirow{2}{*}{ Rostral ACC } & $\mathrm{R}$ & $24 / 25$ & 4 & 28 & 12 & 51 & 3.17 \\
\hline & & & 14 & 28 & 14 & - & 2.73 \\
\hline \multirow[t]{3}{*}{ Mid ACC } & $\mathrm{R} / \mathrm{L}$ & $24 / 32$ & 6 & 4 & 38 & 284 & 3.26 \\
\hline & & & -2 & 24 & 30 & & 3.00 \\
\hline & & & -8 & 22 & 36 & & 2.90 \\
\hline \multirow[t]{3}{*}{ Premotor cortex } & $\mathrm{L}$ & $9 / 6$ & -40 & 10 & 50 & 319 & 3.91 \\
\hline & & & -36 & 24 & 54 & - & 3.21 \\
\hline & & & -32 & 14 & 52 & - & 2.81 \\
\hline SI & $\mathrm{R}$ & 2 & 24 & -40 & 64 & 291 & 3.83 \\
\hline Thalamus & $\mathrm{L}$ & & -16 & -6 & 10 & 38 & 3.15 \\
\hline \multirow{4}{*}{ Angular gyrus } & $\mathrm{L}$ & 40 & -64 & -40 & 32 & 390 & 3.65 \\
\hline & & & -48 & -48 & 34 & - & 3.56 \\
\hline & & & -58 & -60 & 34 & - & 3.42 \\
\hline & $\mathrm{R}$ & $39 / 40$ & 54 & -52 & 28 & 77 & 3.17 \\
\hline \multirow[t]{3}{*}{ DMPFC } & $\mathrm{R} / \mathrm{L}$ & 9 & 0 & 46 & 44 & 168 & 3.22 \\
\hline & & & 0 & 36 & 44 & - & 2.97 \\
\hline & & & -6 & 48 & 34 & - & 2.81 \\
\hline \multirow[t]{2}{*}{ SMA } & $\mathrm{L}$ & 8 & -2 & 24 & 56 & 51 & 3.19 \\
\hline & $\mathrm{R}$ & 6 & 10 & 18 & 62 & 20 & 3.06 \\
\hline Posterior parietal cortex & $\mathrm{R}$ & 7 & 20 & -66 & 36 & 27 & 3.10 \\
\hline Occipital cortex & $\mathrm{R}$ & 18 & 18 & -90 & 16 & 36 & 3.01 \\
\hline \multirow[t]{8}{*}{ Cerebellum } & $\mathrm{R}$ & & 16 & -80 & -32 & 665 & $4.01 *$ \\
\hline & & & 18 & -72 & -24 & - & 3.85 \\
\hline & & & 34 & -84 & -24 & - & 3.70 \\
\hline & & & 42 & -64 & -38 & 109 & 3.00 \\
\hline & & & 36 & -58 & -34 & - & 2.97 \\
\hline & & & 50 & -68 & -34 & - & 2.75 \\
\hline & & & 8 & -46 & -18 & 13 & 2.94 \\
\hline & & & 44 & -74 & -44 & 11 & 2.78 \\
\hline Fusiform gyrus & $\mathrm{R}$ & 19 & 30 & -72 & -10 & 33 & 2.95 \\
\hline \multirow[t]{2}{*}{ Precuneus } & $\mathrm{L}$ & 7 & -2 & -72 & 54 & 13 & 2.87 \\
\hline & $\mathrm{R}$ & 7 & 4 & -72 & 40 & 34 & 2.83 \\
\hline Low pain $>$ high pain & & & & & & & \\
\hline SI & $\mathrm{L}$ & 3 & -58 & -8 & 36 & 56 & 3.58 \\
\hline Temporal gyrus & $\mathrm{L}$ & 20 & -40 & -16 & -22 & 41 & 3.55 \\
\hline
\end{tabular}

Activations which survive $P<0.05$ cluster-level corrected for multiple comparisons across the whole brain (with $P<0.001$ at the voxel level) are marked by an asterisk. Other activations survive $P<0.005$ (uncorrected). $\mathrm{L}=$ left, $\mathrm{R}=$ right; $\mathrm{DLPFC}=$ dorsolateral prefrontal cortex, $\mathrm{ACC}=$ anterior cingulate cortex, $\mathrm{OFC}=$ orbitofrontal cortex, $\mathrm{SI}=$ primary somatosensory cortex, $\mathrm{DMPFC}=$ dorsomedial prefrontal cortex, SMA = supplementary motor area.

nucleus (see Table 4). The opposite side of the interaction [(high low pain $\left.)_{\text {hard task }}-(\text { high }- \text { low pain })_{\text {easy task }}\right]$, i.e., $(D-C)-$ $(B-A)$ (see Fig. 1) tests instead for pain-related brain areas that exhibit a more pronounced activity in the hard compared to the easy task condition. For this analysis, no significant effects were observed. However, in the additional exploratory analysis, further 


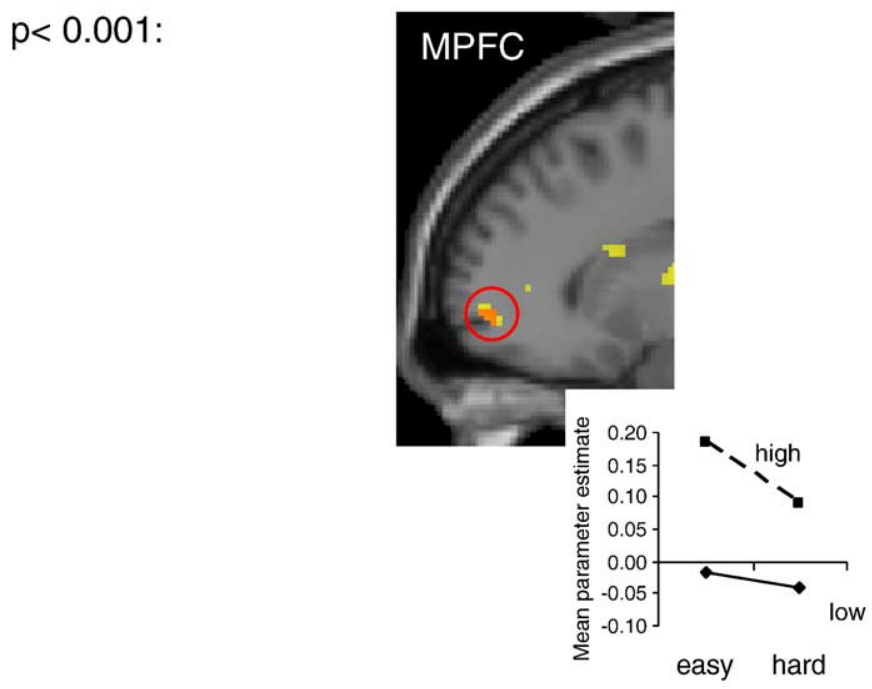

$\mathrm{p}<0.005$ :

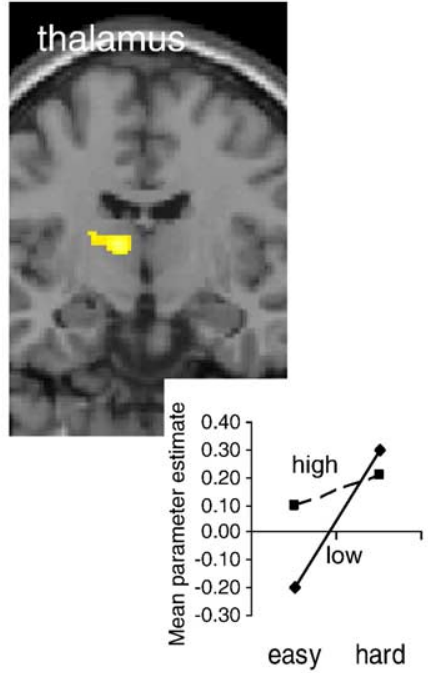

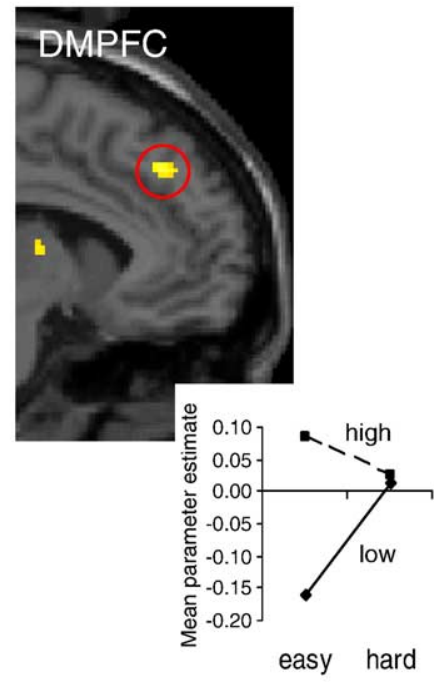

Fig. 5. Interaction [(high - low pain $)_{\text {easy task }}-(\text { high }- \text { low pain })_{\text {hard task }}$. The pain-related activation was stronger during performance of the easy compared to the hard task in the left medial prefrontal cortex (MPFC) and cerebellum $(P<0.001$, uncorrected; minimal cluster size: 10 voxels; shown in orange), indicating that distraction from pain by an attention-demanding task leads to an attenuation in these two regions (upper row). On a lower significance level $(P<0.005$, uncorrected; minimal cluster size: 10 voxels; shown in yellow), additional activations were found in the left thalamus, dorsomedial prefrontal cortex (DMPFC), and left caudate nucleus (lower row).

effects were found in right premotor cortex, and left parahippocampus, SI, putamen, and SMA.

\section{Discussion}

Previous neuroimaging research on pain has tended to concentrate on brain activation to phasic pain stimuli, which may differ substantially from tonic pain states that are encountered in a clinical context. This is highlighted by the recent experimental finding that tonic pain induced by heat stimuli applied to capsaicin-treated skin engages a distinct network of brain regions beyond that observed with a thermal stimulus applied to untreated skin, although both stimulations were matched for subjective intensity (Lorenz et al., 2002). This suggests that the underlying state of injury involves a specific set of neural responses. Capsaicin-induced thermal hyperalgesia, which simulates primary afferent nociceptor activation and subsequent central sensitization as the hallmark of chronic inflammatory or neuropathic pain (Ji and Woolf, 2001), may therefore provide a particularly useful model of chronic pain.

The relationship between pain and attention is of particular interest, as several lines of clinical evidence suggest that attentional mechanisms may be involved in the pathogenesis of some chronic clinical pain states (Vlaeyen and Linton, 2000). However, the exact nature of this interaction between cognitive demand and chronic pain has remained unclear, as has their neurobiological basis. In an experimental approach, we investigated this in capsaicin-induced tonic pain by manipulating not only the level of thermal stimulation, but also the cognitive demand of an unrelated concurrent visual task. Consistent with a behavioral 'interference' effect of attentional demand on pain perception, we found that increasing the cognitive demand of a visual attention task reduced subjective pain ratings for the highintensity stimulation (see Fig. 3). 
Table 3

Main effect of DEMAND OF CONCURRENT COGNITIVE TASK

\begin{tabular}{|c|c|c|c|c|c|c|c|}
\hline \multirow[t]{2}{*}{ Brain region } & \multirow[t]{2}{*}{ Laterality } & \multirow[t]{2}{*}{ Brodmann area } & \multicolumn{3}{|c|}{ Talairach coordinates } & \multirow[t]{2}{*}{ Cluster size } & \multirow[t]{2}{*}{$\overline{\text { Max. } Z}$} \\
\hline & & & $x$ & $y$ & $z$ & & \\
\hline \multicolumn{8}{|c|}{ Hard task $>$ easy task } \\
\hline \multirow[t]{6}{*}{ Premotor cortex } & $\mathrm{L}$ & 6 & -44 & 2 & 38 & 4348 & 5.94 \\
\hline & & 6 & -54 & 4 & 42 & - & 4.94 \\
\hline & $\mathrm{R}$ & 44 & 48 & 12 & 34 & 4836 & 5.33 \\
\hline & & 6 & 30 & -2 & 56 & 4781 & 5.5 \\
\hline & & 6 & 28 & 8 & 48 & - & 5.07 \\
\hline & & 6 & 6 & 16 & 48 & - & 5.04 \\
\hline Occipital lobe & $\mathrm{L}$ & 19 & -24 & -64 & 32 & 13,453 & 5.56 \\
\hline \multirow[t]{2}{*}{ Parietal cortex } & $\mathrm{R}$ & 40 & 36 & -42 & 40 & - & 5.17 \\
\hline & $\mathrm{L}$ & 7 & -16 & -70 & 52 & - & 5.13 \\
\hline Operculum & $\mathrm{R}$ & 44 & 46 & 8 & 26 & - & 5.33 \\
\hline Insula & $\mathrm{R}$ & 48 & 34 & 32 & 4 & - & 5.16 \\
\hline \multirow[t]{3}{*}{ Cerebellum } & $\mathrm{L}$ & - & -10 & -74 & -40 & 1016 & 4.85 \\
\hline & & - & -22 & -70 & -50 & - & 4.23 \\
\hline & $\mathrm{R}$ & - & 4 & -76 & -34 & - & 4.66 \\
\hline \multirow[t]{4}{*}{ Thalamus } & $\mathrm{R}$ & - & 16 & -16 & 16 & 328 & 4.26 \\
\hline & $\mathrm{L}$ & - & -16 & -12 & 20 & 266 & 3.99 \\
\hline & & - & -18 & -26 & 16 & - & 3.67 \\
\hline & & - & -10 & -14 & 8 & - & 3.33 \\
\hline \multicolumn{8}{|c|}{ Easy task $>$ hard task } \\
\hline DMPFC & $\mathrm{L}$ & 8 & -6 & 42 & 54 & 4632 & 5.12 \\
\hline $\mathrm{pCC}$ & $\mathrm{L}$ & 23 & -2 & -50 & 30 & 763 & 4.54 \\
\hline Angular gyrus & $\mathrm{L}$ & 23 & -50 & -62 & 28 & 573 & 4.4 \\
\hline \multirow[t]{2}{*}{ Cerebellum } & $\mathrm{R}$ & - & 44 & -76 & -44 & 405 & 3.94 \\
\hline & $\mathrm{R}$ & - & 36 & -86 & -34 & - & 3.6 \\
\hline \multirow{3}{*}{ Temporal lobe } & $\mathrm{L}$ & 6 & -48 & -2 & -34 & 664 & 3.73 \\
\hline & & 20 & -58 & -10 & -32 & - & 3.68 \\
\hline & & 21 & -62 & -10 & -20 & - & 3.65 \\
\hline
\end{tabular}

$P<0.05$ cluster-level corrected for multiple comparisons across the whole brain (with $P<0.001$ at the voxel level); $\mathrm{L}=$ left, $\mathrm{R}=$ right; $\mathrm{DMPFC}=$ dorsomedial prefrontal cortex, $\mathrm{pCC}=$ posterior cingulate cortex.

Table 4

Interactions between PAIN INTENSITY and DEMAND OF CONCURRENT COGNITIVE TASK

\begin{tabular}{|c|c|c|c|c|c|c|c|}
\hline \multirow[t]{2}{*}{ Brain region } & \multirow[t]{2}{*}{ Laterality } & \multirow[t]{2}{*}{ Brodmann area } & \multicolumn{3}{|c|}{ Talairach coordinates } & \multirow[t]{2}{*}{ Cluster size } & \multirow[t]{2}{*}{ Max. Z } \\
\hline & & & $x$ & $y$ & $z$ & & \\
\hline \multicolumn{8}{|c|}{$(\text { High }- \text { low pain })_{\text {easy task }}-(\text { high }- \text { low pain })_{\text {hard task }}$} \\
\hline MPFC & $\mathrm{L}$ & 11 & -16 & 56 & -4 & 21 & $3.69 *$ \\
\hline \multirow[t]{4}{*}{ Cerebellum } & $\mathrm{L}$ & - & -24 & -80 & -28 & 24 & $3.55^{*}$ \\
\hline & & - & -6 & -56 & -50 & 23 & 3.65 \\
\hline & $\mathrm{R}$ & - & 32 & -62 & -50 & 20 & 2.89 \\
\hline & & - & 36 & -54 & -48 & & 2.78 \\
\hline Thalamus & $\mathrm{L}$ & - & -10 & -10 & 10 & 132 & 3.25 \\
\hline OFC & $\mathrm{R}$ & 11 & 24 & 58 & -6 & 30 & 3.20 \\
\hline DMPFC & $\mathrm{L}$ & 32 & -6 & 38 & 40 & 60 & 3.07 \\
\hline Caudate nucleus & $\mathrm{L}$ & - & -14 & 14 & 18 & 15 & 2.96 \\
\hline \multicolumn{8}{|c|}{$(\text { High }- \text { low pain })_{\text {hard task }}-(\text { high }- \text { low pain })_{\text {easy task }}$} \\
\hline \multirow[t]{3}{*}{ Premotor cortex } & $\mathrm{R}$ & 6 & 48 & -14 & 54 & 45 & 3.23 \\
\hline & & 6 & 54 & -2 & 48 & 37 & 3.16 \\
\hline & & 6 & 34 & -10 & 60 & 17 & 3.10 \\
\hline Parahippocampus & $\mathrm{L}$ & 30 & -26 & -18 & -30 & 67 & 3.41 \\
\hline SI & $\mathrm{L}$ & 1 & -62 & -16 & 40 & 62 & 3.24 \\
\hline Putamen & $\mathrm{L}$ & - & -28 & -2 & -6 & 14 & 3.08 \\
\hline SMA & $\mathrm{L}$ & 6 & -6 & -10 & 56 & 17 & 3.01 \\
\hline
\end{tabular}

Clusters were thresholded on $P<0.001$ (uncorrected) with an extent of at least 10 voxels. The interaction contrast was masked with the contrast map obtained for the main effect of pain thresholded at $P<0.05$ uncorrected. Significant activations are marked with an asterisk.

For exploratory reasons, the same analysis was performed adopting a significance level of $P<0.005$ (uncorrected) at the voxel level and an extent of $\geq 10$ contiguous voxels without masking. $\mathrm{L}=$ left, $\mathrm{R}=$ right; $\mathrm{MPFC}=$ medial prefrontal cortex, $\mathrm{OFC}=$ orbitofrontal cortex, $\mathrm{DMPFC}=$ dorsomedial prefrontal cortex, $\mathrm{SI}=$ primary somatosensory cortex, $\mathrm{SMA}=$ supplementary motor area . 
Turning to the fMRI data, we first identified brain areas where activation varied with stimulation intensity. In a previous study that also used thermal stimulation of capsaicin-pretreated skin, no intensity-dependent increase in brain activity was observed (Lorenz et al., 2002). However, as discussed by the authors, the rather small difference in perceived pain intensity between highand low-level stimulation might have accounted for a lack of effect.

In the present study, pain-intensity-related activations were observed in orbitofrontal and medial prefrontal cortex, right midposterior insula, and cerebellum (Fig. 4). At a more liberal threshold, significant activations were also seen in other 'classical' pain areas such as thalamus, contralateral SI, mid and rostral ACC, left premotor cortex, and right DLPFC (for an overview on pain-related activations, see Peyron et al., 2000). Orbitofrontal activation has been reported in previous studies on acute (Craig et al., 2000; Derbyshire et al., 1997; Petrovic et al., 2000; Rainville et al., 1999), chronic (Apkarian et al., 2001; Hsieh et al., 1995; Rosen et al., 1994), and capsaicin-induced pain (Lorenz et al., 2002). Given the dense connections of orbitofrontal cortex with brain regions mediating affective components of pain (i.e., insula, ACC, and amygdala; see Carmichael and Price, 1995), Lorenz et al. (2002) concluded that orbitofrontal cortex may "... reflect cognitive and emotional responses to perceived tissue pathology". More broadly, it is known to play a central role in motivational learning and action selection depending on the internal or external (i.e., environmental) state (Gallagher et al., 1999; O'Doherty et al., 2004). In this light, our data may fit the behavioral adaptation required following injury, which necessitates reevaluation and relearning of motivational goals.

Besides orbitofrontal and medial prefrontal activations, activity in right mid-posterior insula varied with pain intensity. Craig and coworkers (Craig et al., 2000) reported recently that activation in contralateral mid-posterior insula was positively correlated with temperature level, whereas subjective intensity related more to activation of the right anterior insula. Spinal lamina 1 neurons, which receive input from peripheral nociceptors, project to posterior insula through supraspinal relays (Craig et al., 1994, 1999). Therefore, mid-posterior insula may provide a primary 'interoceptive cortex', specialized for perception of internal bodily states incorporating pain, temperature, itch, and autonomic arousal (Craig, 2003; Critchley et al., 2002). Such an interpretation is consistent with our finding of an effect of pain intensity in this region.

Increased cognitive demand in the unrelated visual task led to higher activation in various areas, including premotor cortex, dorsolateral prefrontal cortex, inferior and superior parietal lobe, and occipital regions (Table 2). These results are consistent with previous research on varying the cognitive demand of a Rapid Serial Visual Presentation (RSVP) task within purely visual studies without any painful stimulation (e.g., see Marois et al., 2000; Rees et al., 1997; Wojciulik and Kanwisher, 1999).

Critically, by manipulating both the intensity of tonic pain and, orthogonally, the level of cognitive demand in the visual attention task, we were able to examine any interactions between these factors. Two specific regions - medial prefrontal cortex and cerebellum - showed a significant interaction. In both these areas, the interaction indicated that the difference between high and low pain stimulation was significantly reduced under high vs. low cognitive demand in the visual task (see Fig. 5). This pattern resembles the interaction found for subjective pain ratings in the behavioral study (see Fig. 3).

These results clearly establish that some of the activations for high-intensity stimulation in capsaicin-induced thermal hyperalgesia do not only depend on the pain stimulation, but also on the cognitive load of other ongoing tasks (as found here for medial prefrontal cortex and cerebellum) while other pain-related activations were not significantly affected by cognitive load (e.g., insula). Furthermore, the results show that an interaction of a cognitive task with an experimental form of pathological pain differs from the interactions observed for acute pain in previous studies (Bantick et al., 2002; Frankenstein et al., 2001; Petrovic et al., 2000; Valet et al., 2004). Particularly for the orbitofrontal cortex, these studies have mainly reported an increase in activation during higher cognitive load which has been interpreted as an inhibitory control of sensory input. However, orbitofrontal and medial prefrontal cortex are very heterogeneous regions which subserve a variety of different functions (Kringelbach and Rolls, 2004).

One interpretation of the medial prefrontal interaction would be that this region may play some direct role in representing subjective pain intensity (or alternatively affective value), given that subjective ratings showed a similar interaction as the fMRI data. This is endorsed by findings that medial prefrontal activation varies with the affective value of stimuli (notably for rewardrelated stimuli, e.g., see Gottfried et al., 2002; O'Doherty et al., 2003). In our study, medial prefrontal activity may thus reflect the representation of tonic aversive affective value.

An interaction between pain perception and task performance was also seen in the left cerebellum, as reported previously for phasic pain (Bantick et al., 2002). Cerebellar activation during pain has been suggested to reflect a latent motor response, for example, suppression of withdrawal movement. Recent studies have highlighted value-dependent learning activity in the cerebellum (Ploghaus et al., 2000; Seymour et al., 2004), and an interaction between intensity and attention is thus not unexpected in the light of contemporary learning theory (Dayan et al., 2000).

Regardless of these remaining interpretative issues, the present findings clearly show that the effect of an unrelated task on some parts of the pain-related network (e.g., insula) was below statistical significance while other parts (medial prefrontal cortex and cerebellum) were clearly affected by the cognitive load of the visual task. There is cumulating evidence that patients suffering from persistent pain are characterized by a tendency to extensively monitor pain and related stimuli (Roelofs et al., 2002; Vlaeyen and Linton, 2000). Accordingly, interventions focusing on attentional processes have been demonstrated to ameliorate chronic pain (McCracken and Turk, 2002), as also shown for the experimental model here.

Although capsaicin-induced pain resembles chronic pain with respect to underlying neural processes of central sensitization (Koltzenburg et al., 1994; Petersen and Rowbotham, 1999; Simone et al., 1989), experimental models can only partly reflect the complexity of chronic pain so that clinical implications are limited. While functional neuroimaging of attentional effects upon pain in clinical populations is still required, the present investigation illustrates that combining an experimental model of pain with functional neuroimaging in normal subjects can provide new insights into the neural mechanisms of tonic pain and its amelioration by cognitive factors. 


\section{Acknowledgments}

This work was supported by a Wellcome Trust Program Grant to R.J.D. The participation of K.W. was supported by the German Research Society. We would like to thank Nikolaus Weiskopf for very helpful discussions and Johannes Schulz, and Pia Rotshtein for comments on previous versions of the manuscript.

\section{References}

Altier, N., Stewart, J., 1999. The role of dopamine in the nucleus accumbens in analgesia. Life Sci. 65 (22), 2269-2287.

Apkarian, A.V., Thomas, P.S., Krauss, B.R., Szeverenyi, N.M., 2001. Prefrontal cortical hyperactivity in patients with sympathetically mediated chronic pain. Neurosci. Lett. 311 (3), 193-197.

Bantick, S.J., Wise, R.G., Ploghaus, A., Clare, S., Smith, S.M., Tracey, I., 2002. Imaging how attention modulates pain in humans using functional MRI. Brain 125 (2), 310-319.

Baron, R., Baron, Y., Disbrow, E., Roberts, T.P., 1999. Brain processing of capsaicin-induced secondary hyperalgesia: a functional MRI study. Neurology 53 (3), 548-557.

Brooks, J.C., Nurmikko, T.J., Bimson, W.E., Singh, K.D., Roberts, N., 2002. fMRI of thermal pain: effects of stimulus laterality and attention. NeuroImage 15 (2), 293-301.

Carmichael, S.T., Price, J.L., 1995. Limbic connections of the orbital and medial prefrontal cortex in macaque monkeys. J. Comp Neurol. 363 (4), $615-641$.

Craig, A.D., 2003. Interoception: the sense of the physiological condition of the body. Curr. Opin. Neurobiol. 13 (4), 500-505.

Craig, A.D., Bushnell, M.C., Zhang, E.-T., Blomqvist, A., 1994. A thalamic nucleus specific for pain and temperature sensation. Nature $372,770-773$.

Craig, A.D., Zhang, E.T., Blomqvist, A., 1999. A distinct thermoreceptive subregion of lamina I in nucleus caudalis of the owl monkey. J. Comp. Neurol. 404 (2), 221-234.

Craig, A.D., Chen, K., Bandy, D., Reiman, E.M., 2000. Thermosensory activation of insular cortex. Nat. Neurosci. 3 (2), 184-190.

Critchley, H.D., Melmed, R.N., Featherstone, E., Mathias, C.J., Dolan, R.J., 2002. Volitional control of autonomic arousal: a functional magnetic resonance study. NeuroImage 16 (4), 909-919.

Crombez, G., Eccleston, C., Baeyens, F., Eelen, P., 1997. Habituation and the interference of pain with task performance. Pain 70 (2-3), $149-154$.

Crombez, G., Eccleston, C., Van den, B.A., Goubert, L., van Houdenhove, B., 2004. Hypervigilance to pain in fibromyalgia: the mediating role of pain intensity and catastrophic thinking about pain. Clin. J. Pain 20 (2), 98-102.

Dayan, P., Kakade, S., Montague, P.R., 2000. Learning and selective attention. Nat. Neurosci. 3, 1218-1223 (Suppl.).

Dehghani, M., Sharpe, L., Nicholas, M.K., 2003. Selective attention to pain-related information in chronic musculoskeletal pain patients. Pain $105(1-2), 37-46$.

Deichmann, R., Gottfried, J.A., Hutton, C., Turner, R., 2003. Optimized EPI for fMRI studies of the orbitofrontal cortex. NeuroImage 19, $430-441$

Deichmann, R., Schwarzbauer, C., Turner, R., 2004. Optimisation of the 3D MDEFT sequence for anatomical brain imaging: technical implications at 1.5 and $3 \mathrm{~T}$. NeuroImage 21 (2), 757-767.

Derbyshire, S.W.G., Jones, A.K.P., Gyulai, F., Clark, S., Townsend, D., Firestone, L.L., 1997. Pain processing during three levels of noxious stimulation produces differential patterns of central activity. Pain 73, $431-445$.

Dick, B., Eccleston, C., Crombez, G., 2002. Attentional functioning in fibromyalgia, rheumatoid arthritis, and musculoskeletal pain patients. Arthritis Rheum. 47 (6), 639-644.
Eccleston, C., 1995. Chronic pain and distraction: an experimental investigation into the role of sustained and shifting attention in the processing of chronic persistent pain. Behav. Res. Ther. 33 (4), $391-405$.

Evans, A.C., Collins, D.L., Mills, S.R., Brown, E.D., Kelly, R.L., Peters, T.M., 1993. 3D statistical neuroanatomical models from 305 MRI volumes. Proc. IEEE-Nucl. Sci. Symp. Med. Imaging 1-3, $1813-1817$.

Fitzgerald, M., 1983. Capsaicin and sensory neurons. A review. Pain 15, $109-130$.

Frankenstein, U.N., Richter, W., McIntyre, M.C., Remy, F., 2001. Distraction modulates anterior cingulate gyrus activations during the cold pressor test. NeuroImage 14 (4), 827-836.

Friston, K.J., Ashburner, J., Frith, C.D., Poline, J.-B., Heather, J.D., Frackowiak, R.S.J., 1995a. Spatial registration and normalization of images. Hum. Brain Mapp. 2, 1-25.

Friston, K.J., Holmes, A.P., Worsley, K.P., Poline, J.-B., Frith, C.D., Frackowiak, R.S.J., 1995b. Statistical parametric maps in functional imaging: a general linear approach. Hum. Brain Mapp. 2, $189-210$.

Frot, M., Feine, J.S., Bushnell, M.C., 2004. Sex differences in pain perception and anxiety. A psychophysical study with topical capsaicin. Pain 108 (3), 230-236.

Gallagher, M., McMahan, R.W., Schoenbaum, G., 1999. Orbitofrontal cortex and representation of incentive value in associative learning. J. Neurosci. 19 (15), 6610-6614.

Gottfried, J.A., O'Doherty, J., Dolan, R.J., 2002. Appetitive and aversive olfactory learning in humans studied using event-related functional magnetic resonance imaging. J. Neurosci. 22 (24), 10829-10837.

Grace, G.M., Nielson, W.R., Hopkins, M., Berg, M.A., 1999. Concentration and memory deficits in patients with fibromyalgia syndrome. J. Clin. Exp. Neuropsychol. 21 (4), 477-487.

Grigsby, J., Rosenberg, N.L., Busenbark, D., 1995. Chronic pain is associated with deficits in information processing. Percept. Mot. Skills 81 (2), 403-410.

Hasenbring, M., 2000. Attentional control of pain and the process of chronification. Prog. Brain Res. 129, 525-534.

Hodes, R.L., Howland, E.W., Lightfoot, N., Cleeland, C.S., 1990. The effects of distraction on responses to cold pressor pain. Pain 41 (1), $109-114$.

Hsieh, J.-C., Belfrage, M., Stone-Elander, S., Hansson, P., Ingvar, M., 1995. Central presentation of chronic ongoing neuropathic pain studied by positon emission tomography. Pain 63, 225-236.

Hunt, S.P., Mantyh, P.W., 2001. The molecular dynamics of pain control. Nat. Rev., Neurosci. 2 (2), 83-91.

Ji, R.R., Woolf, C.J., 2001. Neuronal plasticity and signal transduction in nociceptive neurons: implications for the initiation and maintenance of pathological pain. Neurobiol. Dis. 8 (1), 1-10.

Kewman, D.G., Vaishampayan, N., Zald, D., Han, B., 1991. Cognitive impairment in musculoskeletal pain patients. Int. J. Psychiatry Med. 21 (3), 253-262.

Klede, M., Handwerker, H.O., Schmelz, M., 2003. Central origin of secondary mechanical hyperalgesia. J. Neurophysiol. 90 (1), 353-359.

Koltzenburg, M., Lundberg, L.E.R., Torebjörk, H.E., 1992. Dynamic and static components of mechanical hyperalgesia in human hairy skin. Pain 51, 207-219.

Koltzenburg, M., Torebjork, H.E., Wahren, L.K., 1994. Nociceptor modulated central sensitization causes mechanical hyperalgesia in acute chemogenic and chronic neuropathic pain. Brain 117, 579-591.

Koppert, W., Dern, S.K., Sittl, R., Albrecht, S., Schuttler, J., Schmelz, M., 2001. A new model of electrically evoked pain and hyperalgesia in human skin: the effects of intravenous alfentanil, $S(+)$-ketamine, and lidocaine. Anesthesiology 95 (2), 395-402.

Kringelbach, M.L., Rolls, E.T., 2004. The functional neuroanatomy of the human orbitofrontal cortex: evidence from neuroimaging and neuropsychology. Prog. Neurobiol. 72 (5), 341-372. 
LaMotte, R.H., Shain, C.N., Simone, D.A., Tsai, E.F., 1991. Neurogenic hyperalgesia: psychophysical studies of underlying mechanisms. J. Neurophysiol. 66, 190-211.

LaMotte, R.H., Lundberg, L.E., Torebjork, H.E., 1992. Pain, hyperalgesia and activity in nociceptive $\mathrm{C}$ units in humans after intradermal injection of capsaicin. J. Physiol. 448, 749-764.

Lavie, N., 1995. Perceptual load as a necessary condition for selective attention. J. Exp. Psychol. Hum. Percept. Perform. 21, 451-468.

Lorenz, J., Bromm, B., 1997. Event-related potential correlates of interference between cognitive performance and tonic experimental pain. Psychophysiology 34 (4), 436-445.

Lorenz, J., Cross, D., Minoshima, S., Morrow, T., Paulson, P., Casey, K., 2002. A unique representation of heat allodynia in the human brain. Neuron 35 (2), 383-393.

Marois, R., Chun, M.M., Gore, J.C., 2000. Neural correlates of the attentional blink. Neuron 28 (1), 299-308.

May, A., Bahra, A., Buchel, C., Frackowiak, R.S., Goadsby, P.J., 2000. PET and MRA findings in cluster headache and MRA in experimental pain. Neurology 55 (9), 1328-1335.

McCracken, L.M., Turk, D.C., 2002. Behavioral and cognitive-behavioral treatment for chronic pain: outcome, predictors of outcome, and treatment process. Spine 27 (22), 2564-2573.

O'Doherty, J., Critchley, H., Deichmann, R., Dolan, R.J., 2003. Dissociating valence of outcome from behavioral control in human orbital and ventral prefrontal cortices. J. Neurosci. 23 (21), 7931-7939.

O’Doherty, J., Rolls, E.T., Kringelbach, M., 2004. Neuroimaging studies of cross-modal integration for emotion. In: Calvert, G., Spence, C., Stein, B.E. (Eds.), The Handbook of Multisensory Processes. MIT Press, Cambridge, MA, pp. 563-579.

Petersen, K.L., Rowbotham, M.C., 1999. A new human experimental pain model: the heat capsaicin sensitization model. NeuroReport 10, $1511-1516$

Petrovic, P., Petersson, K.M., Ghatan, P.H., Stone-Elander, S., Ingvar, M., 2000. Pain-related cerebral activation is altered by a distracting cognitive task. Pain 85, 19-30.

Peyron, R., Laurent, B., Garcia-Larrea, L, 2000. Functional imaging of brain responses to pain. A review and meta-analysis. Neurophysiol. Clin. 30 (5), 263-288.

Ploghaus, A., Tracey, I., Clare, S., Gati, J.S., Rawlins, J.N.P., Matthews, P.M., 2000. Learning about pain: the neural substrate of the prediction error for aversive events. Proc. Natl. Acad. Sci. U. S. A. 97 (16), $9281-9286$

Rainville, P., Hofbauer, R.K., Paus, T., Duncan, G.H., Bushnell, M.C., Price, D.D., 1999. Cerebral mechanisms of hypnotic induction and suggestion. J. Cogn. Neurosci. 11 (1), 110-125.
Rees, G., Frith, C.D., Lavie, N., 1997. Modulating irrelevant motion perception by varying attentional load in an unrelated task. Science 278 (5343), 1616-1619.

Remy, F., Frankenstein, U.N., Mincic, A., Tomanek, B., Stroman, P.W., 2003. Pain modulates cerebral activity during cognitive performance. NeuroImage 19 (3), 655-664.

Roelofs, J., Peters, M.L., Zeegers, M.P., Vlaeyen, J.W., 2002. The modified Stroop paradigm as a measure of selective attention towards painrelated stimuli among chronic pain patients: a meta-analysis. Eur. J. Pain 6 (4), $273-281$.

Rosen, S.D., Paulesu, E., Frith, C.D., Frackowiak, R.S., Davies, G.J., Jones, T., Camici, P.G., 1994. Central nervous pathways mediating angina pectoris. Lancet 344 (8916), 147-150.

Schmelz, M., Schmid, R., Handwerker, H.O., Torebjörk, H.E., 2000. Encoding of burning pain from capsaicin-treated human skin in two categories of unmyelinated nerve fibres. Brain 123, $560-571$.

Seymour, B., O'Doherty, J.P., Dayan, P., Koltzenburg, M., Jones, A.K., Dolan, R.J., Friston, K.J., Frackowiak, R.S., 2004. Temporal difference models describe higher-order learning in humans. Nature 429 (6992), $664-667$.

Simone, D.A., Baumann, T.K., LaMotte, R.H., 1989. Dose-dependent pain and mechanical hyperalgesia in humans after intradermal injection of capsaicin. Pain 38, 99-107.

Terkelsen, A.J., Andersen, O.K., Molgaard, H., Hansen, J., Jensen, T.S., 2004. Mental stress inhibits pain perception and heart rate variability but not a nociceptive withdrawal reflex. Acta Physiol. Scand. 180 (4), $405-414$

Tracey, I., Ploghaus, A., Gati, J.S., Clare, S., Smith, S., Menon, R.S., Matthews, P.M., 2002. Imaging attentional modulation of pain in the periaqueductal gray in humans. J. Neurosci. 22 (7), 2748-2752.

Valet, M., Sprenger, T., Boecker, H., Willoch, F., Rummeny, E., Conrad, B., Erhard, P., Tolle, T.R., 2004. Distraction modulates connectivity of the cingulo-frontal cortex and the midbrain during pain-An fMRI analysis. Pain 109 (3), 399-408.

Vlaeyen, L.W.S., Linton, S.A., 2000. Fear-avoidance and its consequences in chronic musculoskeletal pain:a state of the art. Pain 85, $317-332$

Witting, N., Kupers, R.C., Svensson, P., Arendt-Nielsen, L., Gjedde, A., Jensen, T.S., 2001. Experimental brush-evoked allodynia activates posterior parietal cortex. Neurology 57 (10), 1817-1824.

Wojciulik, E., Kanwisher, N., 1999. The generality of parietal involvement in visual attention. Neuron 23 (4), 747-764.

Woolf, C.J., Salter, M.W., 2000. Neuronal plasticity: increasing the gain in pain. Science $288,1765-1768$ 